\title{
Design and Practice of EMI Teaching Method in Electric Network Principle Course
}

\author{
Guangjin Peng, Zhihong Fu, Qian Zhang, and Chunyan Li
}

\begin{abstract}
Teaching about AC circuit of Electric network principle course in full English is very difficult, in this paper' EMI (English as the medium of instruction) teaching method was introduced. Firstly, supply study documents to students about knowledge points, emphases and difficult points of $\mathrm{AC}$ circuit. Next, assign group works before class. At last, carry on group demonstration and discussion during class, teacher supply comments. According to feedback and quiz scores of COOP (Co-operative Education Program) of Chongqing University students, EMI teaching method had high efficiency and good impact.
\end{abstract}

Index Terms-EMI, Electric network principle, AC circuit COOP.

\section{INTRODUCTION}

\section{A. English as the Medium of Instruction (EMI)}

There appears to be a fast-moving worldwide shift, in non-anglophone countries, from English being taught as a foreign language (EFL) to English being the medium of instruction (EMI) for academic subjects such as science, mathematics, geography and medicine. Generally the definition of EMI is [1]:

The use of the English language to teach academic subjects in countries or jurisdictions where the first language of the majority of the population is not English.

This definition is important in that it provides a conceptual separation between EMI and content and language integrated learning (CLIL). Whereas CLIL is contextually situated (with its origins in the European ideal of plurilingual competence for EU citizens), EMI has no specific contextual origin. Whereas CLIL does not mention which second, additional or foreign language academic subjects are to be studied in, EMI makes it quite clear that the language of education is English, with all the geopolitical and sociocultural implications that this may entail. Whereas CLIL has a clear objective of furthering both content and language as declared in its title, EMI does not (necessarily) have that objective.

EMI is increasingly being used in universities, secondary schools and even primary schools. This phenomenon has very important implications for the education of young people. Many empirical researches have been conducted into why and when EMI is being introduced and how it is delivered, so that to know the consequences of using English rather than the

Manuscript received February 20, 2017; revised May 5, 2017.

The authors are with School of Electrical Engineering, Chongqing University, No.174, Shazheng S.T., Shapingba Dist., Chongqing,400030, China (e-mail: pengguangjin@cqu.edu.cn, fuzhihong@cqu.edu.cn, zhangqian@cqu.edu.cn, lichunyan@cqu.edu.cn). first language on teaching, learning, assessing, and teacher professional development.

An overview study of 55 countries around the world about EMI was carried out by the British council.

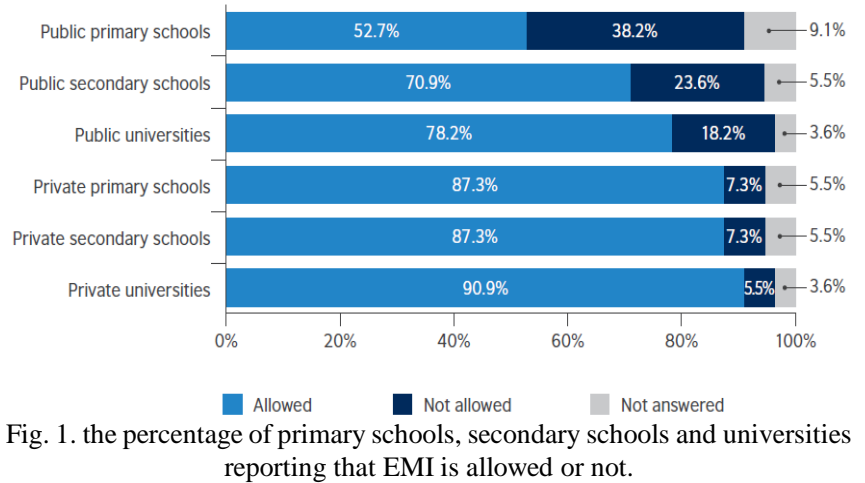

\section{B. EMI in Chongqing University}

From 2013, COOP program was introduced from University of Cincinnati in United State of America by Chongqing University in China.

The author was assigned to receive teaching training in University of Cincinnati of USA in Oct., 2013. This is class picture when the author audited Engineering foundation course, as shown in Fig. 2

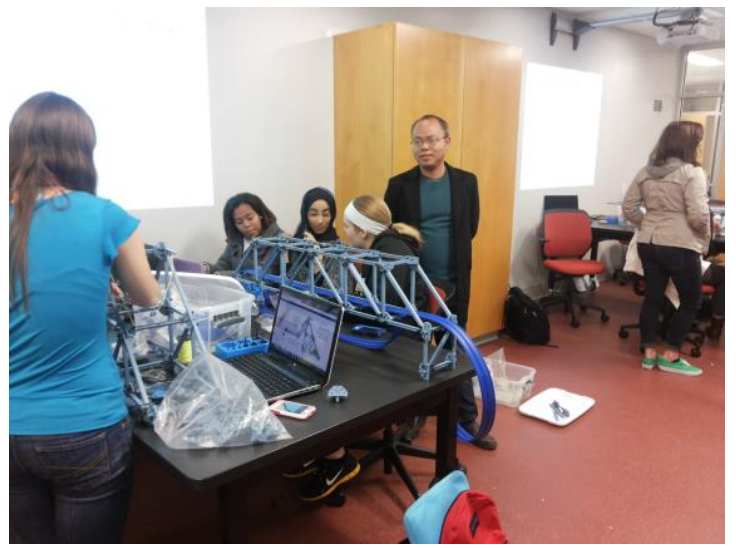

Fig. 2. English as the medium of instruction (EMI) training at University of Cincinnati of USA in Oct., 2013.

In Sep., 2014, 49 china students of Electrical engineering were enrolled in Chongqing University. In order to maintain high teaching quality, all course were presented in English, electric circuit principle was the first major fundamental course [2]. In this paper, EMI teaching method was introduced to the presentation of AC circuit part after I finished several EMI training in USA and China.

Electric circuit principle was the first major fundamental course, and AC circuit was a very difficult part, AC circuit is 
also the mainly used electric energy form nowadays, master degree of AC circuit will affect the study effect of subsequent parts such as electric technology and electric motor. So, this paper focused on how to improve teaching effect of $\mathrm{AC}$ circuit by use of EMI.

International academy publishing reserves the right to do the final formatting of your paper.

\section{LEARNING COURSEWARE AND LEARNING GUIDE DESIGN}

TABLE I: THE STUDY GUIDE OF AC CIRCUIT

\begin{tabular}{|c|c|c|c|c|}
\hline No. & $\begin{array}{l}\text { Knowledge } \\
\text { name }\end{array}$ & $\begin{array}{l}\text { Class } \\
\text { hour } \\
\text { s }\end{array}$ & $\begin{array}{l}\text { Basic } \\
\text { requirement }\end{array}$ & Main concepts \\
\hline 1 & $\begin{array}{l}\text { Three elements } \\
\text { of sinusoidal } \\
\text { AC variables }\end{array}$ & 2 & $\begin{array}{l}\text { Master the } \\
\text { concepts of } \\
\text { three elements }\end{array}$ & $\begin{array}{l}\text { Cycle, frequency, } \\
\text { active value, phase, } \\
\text { phase difference }\end{array}$ \\
\hline 2 & $\begin{array}{l}\text { Phasor } \\
\text { analysis }\end{array}$ & 2 & $\begin{array}{l}\text { Master its } \\
\text { concept and } \\
\text { principle }\end{array}$ & $\begin{array}{l}\text { Phasor, angle, } \\
\text { phasor diagram }\end{array}$ \\
\hline 3 & $\begin{array}{l}\text { Complex } \\
\text { operation }\end{array}$ & 1 & $\begin{array}{l}\text { Master addition, } \\
\text { subtraction, } \\
\text { multiplication } \\
\text { and division } \\
\text { operation of } \\
\text { complexes }\end{array}$ & $\begin{array}{l}\text { Triangular } \\
\text { form ,polar form, } \\
\text { exponential form of } \\
\text { complexes }\end{array}$ \\
\hline 4 & AC power & 3 & $\begin{array}{l}\text { Master } \\
\text { calculation of } \\
\text { three AC powers }\end{array}$ & $\begin{array}{l}\text { Active power, } \\
\text { reactive power and } \\
\text { apparent power }\end{array}$ \\
\hline 5 & $\begin{array}{l}\text { Analysis of AC } \\
\text { circuit }\end{array}$ & 4 & $\begin{array}{l}\text { Master how to } \\
\text { solve AC circuit } \\
\text { problems by use } \\
\text { of phasor } \\
\text { analysis }\end{array}$ & $\begin{array}{l}\text { Voltage triangle, } \\
\text { power triangle, } \\
\text { phasor form of } \\
\text { ohm's law ,KCL } \\
\text { and KVL }\end{array}$ \\
\hline 6 & $\begin{array}{l}\text { Resonant AC } \\
\text { circuit and } \\
\text { power factor }\end{array}$ & 2 & $\begin{array}{l}\text { Master concepts } \\
\text { of Resonance } \\
\text { and calculation } \\
\text { of power factor }\end{array}$ & $\begin{array}{l}\text { Series resonance, } \\
\text { parallel resonance, } \\
\text { correction of power } \\
\text { factor }\end{array}$ \\
\hline 7 & $\begin{array}{l}\text { Three phase } \\
\text { system }\end{array}$ & 4 & & \\
\hline
\end{tabular}

According to the $\mathrm{AC}$ circuit sections of the syllabus requirements, main knowledge points include: three elements of sinusoidal AC variables(sinusoidal AC speed (frequency and cycle), magnitudes of sinusoidal AC variable(effective value, instantaneous value and amplitude), change process of sinusoidal AC variable(phase, initial phase and phase difference)), the phasor analysis method of $\mathrm{AC}$ circuit, the basic concept and calculation of the three power forms in the AC circuit(active power, reactive power and apparent power ), AC circuit analysis, resonant circuit and power factor ${ }^{[3]}$. According to the general design principle of EMI teaching method, the interaction between teachers and students should be strengthened, also teacher should encourage students to take the initiative to summarize the teaching content. Therefore, in the teaching process design, AC circuit PPT were firstly designed and supplied to student before class so that it is convenient for students to preview.

In addition, in order to enable students to conduct after-school learning and group exercises, a guide of the AC circuits study was provided to students.

All knowledge of AC circuits consisted of seven points, which included in three chapters. Specific contents was as shown in Table I [3]-[5].

\section{HOMEWORK DESIGN BEFORE ClASS}

In order to allow students to have a full practice and understanding of teaching contents before class, this link is designed before the class, not only to allow students to have a better understanding of the knowledge, but also cultivate the spirit of teamwork.

For each point of knowledge, one or two problems were assigned to students before class, and every class will have two hours, so usually at least four problems will be assigned before class. Because the number of students was 25 , which can be called a small class, 25 students were divided into four groups, three groups consist of six students, one group composed of seven students.

Before class, each group must complete all assigned problems through discussion. During class, teacher randomly asked each group explain a problem solving process.

\section{Class Activities Design}

\section{A. English Proficiency of Students}

In order to achieve good teaching effects, students were asked to describe their own level of their oral proficiency in English and Fig. 3 summarizes their response [6].

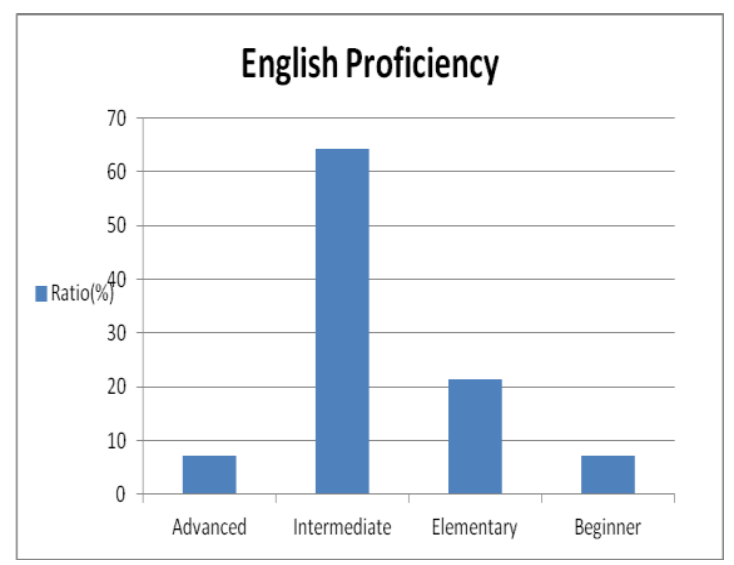

Fig. 3. English proficiency of students

Thus while $7.14 \%$ felt their spoken English was advanced, $64.28 \%$ felt it was intermediate, with $28.57 \%$ describing their level as elementary or beginner. So it is necessary to explain some vocabularies about basic concepts and key knowledge points.

\section{B. Class Activities Plan}

The contents of AC circuit should consume 18 class hours, divided into nine times, then each time two class hours. Each class activities at least were composed of four parts:

First part, teacher should spend 10 to 15 minutes to introduce outline and vocabulary of AC circuits by PPT slides.

Fig. 4 was the PPT slide of Vocabulary of AC circuits, teacher spent some time to introduce their definition or meaning in the beginning of the class.

Fig. 5 was the PPT slide of outline of AC circuits, teacher 
should simply introduce main contents of each section.

\section{Vocabulary}

- Sinusoid, amplitude, period, frequency, phase, argument, phase difference, in phase, opposite phase, lead, lag

- Phasor, complex, phasor diagram, phasor domain/frequency domain, rectangular form, polar form, exponential form

- Impedance, admittance, impedance combination

Fig. 4. Vocabulary of AC circuits.

\section{Outline}

- 9.1 Introduction

- 9.2 Sinusoid

- 9.3 Phasors

- 9.4 Phasor relationship for circuit elements

- 9.5 Impedance and admittance

- 9.6 Kirchhoff's laws in the frequency domain

\section{- 9.7 Impedance combination}

Fig. 5. Outline of AC circuit.

Second part, each group was asked to explain the solving process and comment on solving process of other group.

Third part was the time when teacher evaluated and asked question about solving problem and solving process. The third part was conducting summary, each group finished section summary by discussion or brain storm.

Finally, each group discussed together and supplied one summary paper.

Total class activities plan was shown in Table II.

\begin{tabular}{lll}
\hline \multicolumn{2}{c}{ TABLE II: CLASS ACTIVITIES } \\
\hline 1 & $\begin{array}{l}\text { Activities } \\
\text { name }\end{array}$ & Main contents \\
\hline 2 & Decture & $\begin{array}{l}\text { Introduction of outline and main } \\
\text { concepts }\end{array}$ \\
\hline 3 & $\begin{array}{l}\text { Evaluation of } \\
\text { teacher }\end{array}$ & $\begin{array}{l}\text { Comment on solving process of } \\
\text { students } \\
\text { Emphasis of important tips }\end{array}$ \\
\hline 4 & Summary & Summarize teaching contents \\
\hline \hline
\end{tabular}

\section{Teaching Practice}

According to the COOP training mode of University of Cincinnati in USA, All students were divided into two classes, in one semester only one class stayed at Chongqing University to carry on course study, another class students went to different companies or factories to do internship about 3 to 4 months, and next semester exchanged.

the second batch of joint training of electrical engineering in 2014 had 53 Students in all, they were divided into two classes for teaching, there were 25 students in the fall semester of 2015, conducted teaching of AC circuit by traditional teaching method, there were 28 students in the spring semester of 2016, this time EMI teaching method was conducted [7].

Here mainly introduced teaching practice of EMI for AC circuits.

28 students were classified into 4 groups, each group had 7 student members and one group leader who should undertake the responsibility of group study.

In order to encourage students to develop the habit of active learning and pay attention to the learning process, the performance of the group study was accounted for $10 \%$ of the final course score at the end of the semester, in AC circuit part, there were 18 class hours, each group should have several time scores according to the performance.

Because there was no video courseware, courseware mainly adopted PPT version, additionally a study guide of AC circuit was supplied to the students, in which the focus and difficult knowledge points were introduced.

In the first part, at the beginning of first class, teacher presented attention tips of AC circuits part, and introduced outline and vocabulary.

In the second part, according to homework arrangements before the end of the last class, the teacher asked each group to explain a random problem, each group arranged at least 2-3 members on the platform to display their preparation, during introduction, other group could ask questions and supply suggestions about solving processes, the group performance of this section would be degraded, at the end of the section teacher determined group scores according to the performance of each group, usually group score was included in the final course scores.

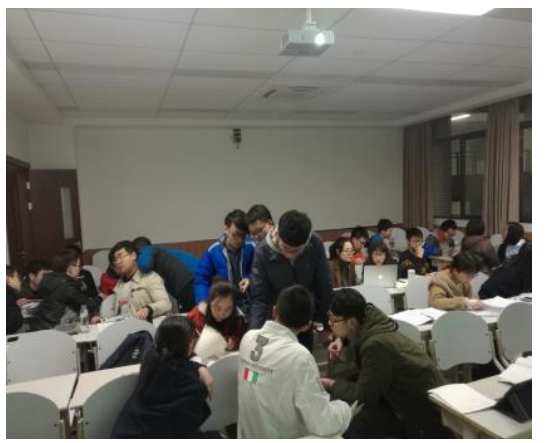

Fig. 6. Group discussion in class.

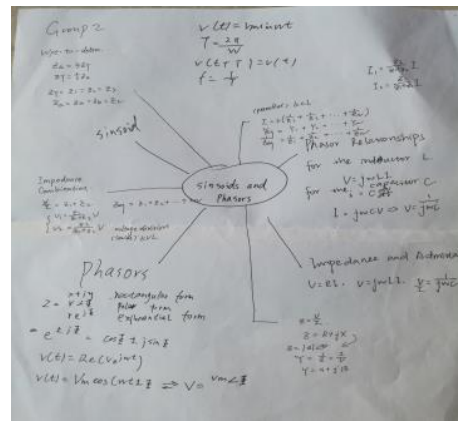

Fig. 7. Group discussion result of students

In the third part, class discussion was carried on, the students asked questions about concepts and difficulties, each knowledge point were analyzed and discussed, the teacher used this time to arrange discussion of every knowledge point, 
put forward some questions, asked students to answer so as to ensure that students had mastered the basic knowledge of all points and concepts.

Fig. 6 showed class discussion in one class, from figure we can see all students joined group discussion very actively.

In the fourth part, students spent some time to summarize learning contents each time in group form, each group was asked to hand out summary papers at last.

Fig. 7 was a summary paper of sinusoid and phasors section of the second group.

\section{TEACHING EFFECT ANALYSIS}

\section{A. Students Performance}

From the teaching situation of 18 hours of class teaching, because students had many other courses to learn at same time ,so they had very great study pressure, there were too many classes in one week, the preparation and preview before class seemed to be slightly inadequate, meanwhile textbooks and courseware were English, which influenced the learning effect of students.

During class some group couldn't complete showing how to solve the homework problems, participation enthusiasm of some students was not too high.

Most students felt that summary part was the most favorite, they could find the most important and difficult knowledge points of each section or chapters.

\section{B. Course Evaluation}

In order to test the teaching effect of EMI teaching method, in spring semester of 2016, after the teaching of AC circuit, 1 hour closed book quiz was carried on, including three problems which were exactly same in fall semester of 2015, from the students' quiz scores, compared with the 2015 fall semester, average test scores increased obviously in 2016 spring semester, more than 85 High segment ratio also increased, students number below 65 points decreased, practice showed that the overall effect of the application of EMI teaching method was good, but need to pay more attention to improving all the students' participation degree in future.

TABLE III: STUDENTS DEGRADING METHODS

\begin{tabular}{llcc}
\hline \hline No. & Section & $\begin{array}{c}\text { Traditional } \\
\text { Method }\end{array}$ & EMI \\
\hline 1 & Present ratio & $\sqrt{ }$ & $\sqrt{ }$ \\
\hline 2 & Home works & $\sqrt{ }$ & $\sqrt{ }$ \\
\hline 3 & Quiz & $\times$ & $\sqrt{ }$ \\
\hline 4 & Laboratory & $\sqrt{ }$ & $\sqrt{ }$ \\
\hline 5 & Group study & $\times$ & $\sqrt{ }$
\end{tabular}

As for the final score, after introducing EMI, several study sections were included, among them, present ratio occupied $5 \%$, home works $20 \%$, laboratory $10 \%$, quiz $10 \%$, middle term examination $15 \%$, final examination $40 \%$.

Table III showed the main difference of students degrading methods between traditional teaching method and EMI. Compared with traditional teaching method, section performance scores of EMI occupied much more percentages, which focused more on learning processes.

\section{Feedback from Students}

From the collection of student feedback for EMI teaching method, students gave high overall evaluation on the EMI teaching method reform, $85.71 \%$ of the students thought that the teaching effect was better than that of the traditional teaching methods ,new EMI teaching method could greatly mobilize the initiative and enthusiasm of the students participation in the teaching process, there were $35.71 \%$ of the students felt that the courseware quality, time distribution, English proficiency of teachers and grouping method should be improved.

\section{CONCLUSION}

Compared with traditional teaching method, EMI teaching method focused more on learning processes, which can raise the study activeness of students. Meanwhile, according to EMI teaching method could supply more scientific and reasonable course evaluation method.

There were too many knowledge points in electric circuit principle courses, among them, the teaching content of $\mathrm{AC}$ circuit was very important and difficult, so for teachers and students it was a great challenge. In this paper, the teaching practice of EMI teaching method was carried on to the AC circuit, from the final teaching effect and students' feedback information, the overall teaching effect of EMI teaching method was good, but also needs to be improved and perfected further.

In the future, We will continue to improve English proficiency of teachers and students, improve all teaching sections of EMI, so as to achieve much better teaching effect of EMI in this course.

\section{REFERENCES}

[1] J. Dearden, "English as a medium of instruction-a growing global phenomenon," British Consul report, pp. 1-10, March 2014.

[2] J. Cai, "A feasibility study of full English teaching — A case study of the course of "public relations" in Fudan University," Foreign Languages in China Journal, vol. 7, no. 6, pp. 61-67, December 2010.

[3] C. K. Alexander, Matthew n. o. Sadiku. Fundmentals of Electric Circuits, McGraw-Hill company, 2013, vol. 11, ch. 9, pp. 367-412.

[4] D. Chen, "The teaching design of three elements of sinusoidal alternating current," Shangqing Journal, vol. 21, pp. 96-98, Sep. 2016.

[5] G. Peng, "The teaching experience of AC circuit of electr-technics course," Education Forum Journal, vol. 36, pp. 66-67, Sep. 2013.

[6] H. Liu, "Thinking on the three elements of sinusoidal alternating current circuit," Examination weekly Journal, vol. 76, pp. 34-36, Jan. 2012

[7] Y. Ying, "Problems and countermeasures in EMI teaching and evaluation system of Chinese and foreign cooperation in running schools," Course Education Study Journal, vol. 31, pp. 36-39, December 2014.

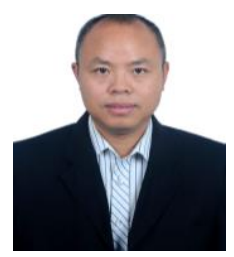

Guangiin Peng is lecturer. He was born on June 27th 1970, in Longhui county of Hunan province, China. He got the Ph.D of Chongqing University in December 31 st 2010 in electrical engineering. 